\title{
A irrupção do ódio na internet: traços discursivos de sua manifestação no Facebook
}

\author{
José Gaston Hilgert" \\ Adalberto Bastos Neto
}

\section{Resumo}

Estuda-se, neste artigo, a irrupção do ódio na internet, focalizando traços discursivos de sua manifestação no Facebook. O ponto de partida da discussão são manifestações de internautas sobre o massacre de presos em Manaus, em janeiro de 2017. O acontecimento em foco desencadeou polêmicas de diferentes ordens, com especial destaque para o embate polar entre os, digamos, favoráveis à sumária eliminação de "bandidos" e os contrários ao massacre. À luz de fundamentos da enunciação, configura-se, inicialmente, a natureza enunciativo-interativa das intervenções dos internautas. Definido esse cenário da enunciação, dá-se, a seguir, particular evidência aos percursos figurativos e temáticos que estruturam tanto o discurso do ódio e do aniquilamento quanto as manifestações de oposição a esse discurso.

Palavras-chave: Discurso. Enunciação. Facebook. Hate speech.

\section{Conceitos gerais e configuração do contexto do estudo}

Discute-se neste artigo a irrupção do ódio na internet, focalizando traços discursivos de sua manifestação no Facebook. Para definir o contexto deste estudo, comecemos com esta imagem:

\footnotetext{
Professor de Linguística do Programa de Pós-Graduação em Letras da Universidade Presbiteriana Mackenzie. E-mail: gastonh@uol.com.br

* Doutorando do Programa de Pós-Graduação em Letras da Universidade Presbiteriana Mackenzie. E-mail: adalbastos@hotmail.com
} 
Figura 1 - Menina refugiada, em vestido florido

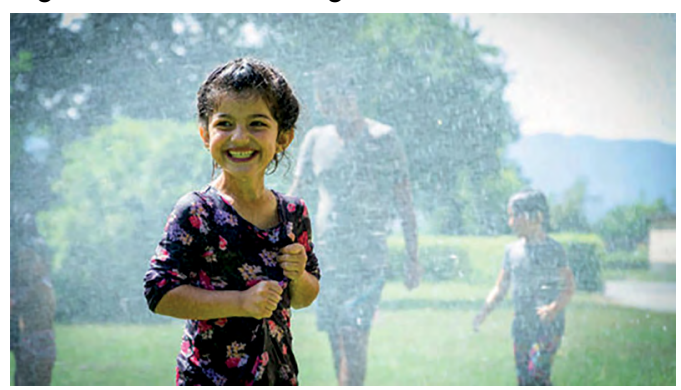

Fonte: Flüchtlingsmädchen im Blumenkleid (http://www. objektiv-fotopreis.at). Acesso em 15 jul. de 2017.

Nela aparece a pequena Dunja, filha de refugiados sírios. Feliz e radiante, ela se refresca na "chuva" provocada pela ação dos bombeiros voluntários da cidade de Feldkirchen an der Donau (Áustria) para amenizar o calor de 36 graus. $\mathrm{O}$ flagrante, feito por Martin Peneder, um dos bombeiros, foi anunciado, em 21 de junho de 2017, como a foto jornalística do ano 2016 da Áustria. Sobre ela, assim se manifestou o júri do concurso:

A imagem ilustra de forma singular o tema político mais importante do ano passado: na crise dos refugiados não se trata somente de vida e morte, de preocupações e medos, de crises nacionais e cercas limítrofes, trata-se de seres humanos, de crianças que se alegram com as mesmas coisas com que todas se alegram. A imagem emociona o espectador. Ela traz esperança. ${ }^{1}$

Com o destaque que lhe foi conferido, a foto com sua mensagem correu mundo. Mas, segundo relata Strobel (2017, p. 29), ainda ao final dos trabalhos daquele dia de calor sufocante, o bombeiro que tirou a foto postou-a no Facebook. Algumas horas depois, num dos surgimentos de sua divulgação on-line, ela apareceu com a seguinte legenda: "Lança-chamas seriam aí a melhor solução".

Quanto mais a fotografia em sua concepção original figurativiza o tema da inocência, da pureza, da alegria e da vida, tanto mais essa legenda é, em seu polo oposto, um registro explícito e chocante de discurso do ódio, que tematiza morte e aniquilação, no contexto polêmico do acolhimento de refugiados sírios e outros na Europa Ocidental.

$\mathrm{Na}$ bibliografia internacional, o discurso do ódio vem denominado de "hate speech" (em alemão Hassrede). Segundo Meibauer, entende-se por "hate speech", em sentido amplo,

[...] a manifestação verbal de ódio contra pessoas ou grupos, que ocorre, particularmente, por meio de expressões destinadas à desqualificação e à difamação de grupos populacionais (MEIBAUER, 2013, p. 01)2.

No discurso do ódio, a língua se torna uma poderosa arma. Com ela, no dizer de (SCHWARZ-FRIESEL, 2013, p. 145-46),

[...] não se pode só convocar para a violência, mas seu uso pode ele próprio ser uma forma destrutiva de exercício da violência. Por meio da língua pessoas são estigmatizadas, discriminadas e demonizadas. $\mathrm{O}$ discurso do ódio se caracteriza particularmente pelo fato de que, por meio dele, seres humanos são feridos em sua dignidade, discriminados como objetos desumanos, caracterizados como criaturas más e inúteis a ponto de não terem direito à existência. ${ }^{3}$

É nesse âmbito, dos estudos do discurso do ódio, que se situa este trabalho. No mesmo quadro conceitual insere-se também o estudo do que costumamos chamar de discursos do preconceito e 
da intolerância. Mesmo que, nas interações cotidianas, uma aparentemente inofensiva manifestação de preconceito não tenha a mesma força ilocucional do que a explosão de um desejo de morte e banimento, ambas as expressões se alimentam, em intensidade diversa, da mesma semântica do ódio.

\section{A delimitação do objeto de estudo}

Na internet, mais especificamente no Facebook, o discurso do ódio assume características próprias. Para discutirmos o tema nesse contexto, tomamos como objeto de análise os assim chamados "comentários" de internautas no Facebook em reação, em princípio, à notícia divulgada pela Rede Globo, na página Jornal Hoje, no dia 2 de janeiro de 2017:

Edição do dia 02/01/2017

Sessenta presos são assassinados em presídio de Manaus

Mortes aconteceram durante uma rebelião que começou domingo (1ํ). Rebelião só foi controlada na manhã dessa segunda-feira (2).

Sessenta presos foram assassinados em um confronto entre duas facções criminosas, durante uma rebelião que começou no domingo (1ํ) e só foi controlada nessa segunda-feira (2), no maior presídio de Manaus. $O$ número oficial de mortos foi divulgado pela Secretaria de Segurança Pública do Estado. ${ }^{4}$

No dia em que acessamos a notícia no Facebook para definir o corpus deste estudo, havia 5,3 mil reações, 262 compartilhamentos e 427 comentários sobre ela, sem contar os comentários de comentários. Para a seleção dos comentários a serem analisados, escolhemos aqueles que, com base em variáveis como quantidade de reações e respostas, o algoritmo do Facebook classifica como "mais relevantes" e concede destaque de visualização.

Já a primeira leitura deles ofereceu evidência ao predomínio absoluto de enunciados como estes vinte (ou semelhantes a eles em forma e conteúdo), os quais elegemos como objeto de análise para este estudo:

1) oba menos 60 pra para mata i rouba vao voubar nu inferno rebanho di cabrunco si tava la nu presidio foi por que algunha ciosa feis por que eu nao to 1

2) Acho justo liberar TDS juntos, e que vença o MELHOR!!! Não que os vencedores ganham a liberdade, mas dá uma jujuba de brinde pela faxina.

(3) Bandido bom é 7 palmos abaixo da terra.

(4) Era pra demorar pelo menos uns noventa dias esta rebelião. Para ver quantos vermes destes o Satanás ia levar. Só sessenta imundos foi pouco.

(5) Aiiiiiiii, um troféu para quem me deu este presente de ano novo! Finalmente o sistema funcionou, tenho certeza de que nenhum destes sessenta marginais voltarão a ter reincidência criminal. Agora é só juntar tudo em um buraco e meter 
fogo para economizar ainda mais o dinheiro público!

(6) O destino é pra quem procura! Se o cara procurar um destino ruim ele vai achar se procurar um destino bom talvez ele ache também. Mais pode ter certeza quem procura acha e esses 60 acharam o que tavam procurando! ...

(7) Foram mortos em guerra de quadrilhas. Nenhum preso foi assassinado gratuitamente. Eles se merecem. Pena que não se matarão a maioria. teriam que ter deixado que terminarem sua vendeta.

(8) Só isso, esses não faram mais mal a ninguém,quem sabe desses quantos eram assassinos também,quantas famílias tiveram que derramar algumas lagrimas vitimas de seus atos insanos!!!

(9) Tem nada não gente! morreu poucos, são simplesmente vagabundos matando vagabundos, era ruim si fosse cidadão de bem $q$ tivesse morrido

(10) Mas sempre tem uma besta pra defender o ser humano que não tá nem aí vai lá e rouba ou mata sem piedade... quando acontecer com você aí conversamos sobre tristeza de perder essa podridão de seres humanos

(11) Nossa não vou nem dormir de tanta tristeza, vou é soltar fogos de artificil kkkkkkkkkk, não vao roubar mais ninguém o ano comecou bem com uma limpeza

(12) Tem que processar o governo por ter interrompido! Análise comigo:60 mortos X R $\$ 2.400,00=R \$ 144.000$
$\mathrm{X} 12=\mathrm{R} \$ 1.728 .000,00$ a menos por ano. Nesses tempos de crise toda economia é bem vinda! se fosse mais, a economia seria maior!

(13) Tem é que morrer toda essa gente maldita, se estão lá é pq fizeram o que não deviam....Enquanto estão morrendo, não estão aqui fora matando os inocentes....Bandido bom é bandido morto.

(14) Nossa que raiva aaa so 80 la tem mas 2000 sacooo ve se na proximo faz o servico certo acaba com tudo 语:

(15) Que bom 2017 começou bem 60 a menos.

(16) Briga entre facções?? Que ótimo.... que se matem!! Todos!!

(17) Quem tiver triste por causa disso. Vai adota um bandido e leva para dentro de casa. Esses vermes tem que ir para o inferno, que o Satanás o tenha. So da prejuízo para o Brasil. Nunca vi fala que esses vermes geram riquezas ao Brasil

(18) Grande coisa esses que morreram. Cada um tem o que merece quantas vidas inocente eles tiraram? O que se faz aqui se paga.

(19) Pocha vida 13 is sò isso,como é o Brasil,kkkkkkk

Podia ser todos mortos, bandido bom e bandido morto 000

(20) Menos 60 !!! Tinha que ter umas 20 chacinas dessa por dia e ainda incluir os diretos humanos na linha de frente

A análise segue em dois momentos: inicialmente trataremos da "cena da enunciação" (MAINGUENEAU, 2006) 
em que a notícia é dada e os comentários são feitos. Depois, dentro dela, focalizaremos o "conteúdo" dos comentários. $\mathrm{Na}$ verdade, a distinção desses dois momentos só visa à organização do texto, pois, na prática, a análise das duas instâncias se desenvolve simultaneamente, já que, segundo Maingueneau, “'o conteúdo' aparece inseparável da cenografia que o porta" (p. 47-48).

\section{O cenário ${ }^{5}$ da enunciação}

A notícia compartilhada pela página do Jornal Hoje no Facebook vale-se de uma imagem extraída da notícia televisionada. Trata-se de uma maneira de conceder maior abrangência à visualização da notícia. Essa ampliação da visualização não é, contudo, isenta de consequências, uma vez que há diferenças bastante significativas na maneira como a mesma notícia é recebida pelo público nas diferentes plataformas.

Figura 2 - Foto de capa da página Jornal Hoje

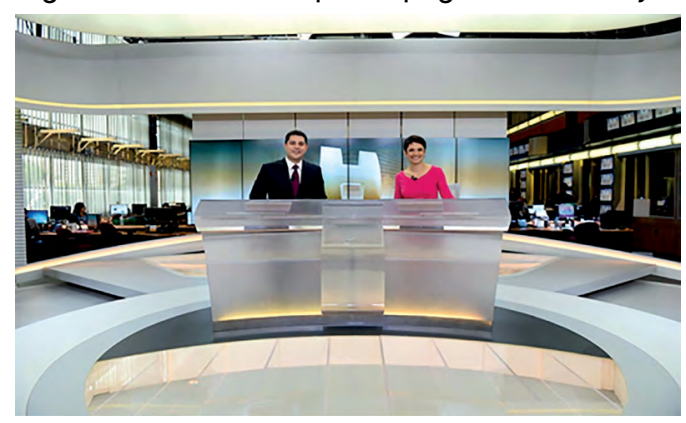

Fonte: Jornal Hoje, TV Globo. ${ }^{6}$

No noticiário visto na tela da televisão, interagem, como atores da enun- ciação, os apresentadores do Jornal e o telespectador. $\mathrm{O}$ texto verbal da notícia (em destaque), para assegurar seu efeito de objetividade e de verdade, tem caráter enuncivo, na medida em que nele estão ausentes as marcas da enunciação. Entra em sintonia com essa dimensão enunciva do verbal o seu sincretismo com a expressão não verbal, como, no caso, a imagem do presídio envolto em fumaça negra.

Figura 3 - Foto da página Jornal Hoje

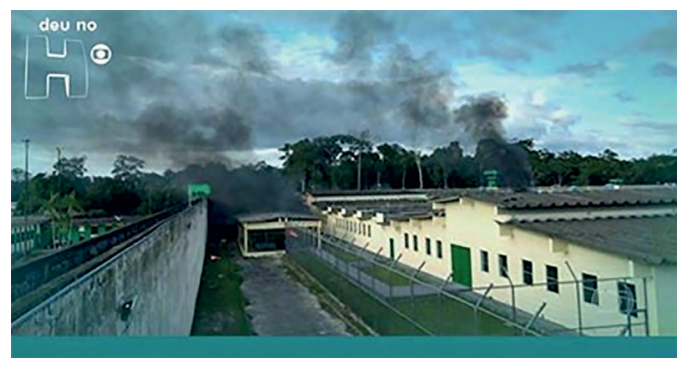

Fonte: Jornal Hoje, TV Globo.

O efeito de realidade produzido pelas imagens não só intensifica o efeito de verdade e de credibilidade da notícia mas também desperta, no telespectador, um estado de comoção.

Esse texto enuncivo é anunciado num cenário enunciativo, na medida em que é enunciativa a relação de olhares entre o eu que fala e o tu que vê e ouve (BARROS, 2006). O encontro desses olhares, no contexto televisivo do noticiário, produz um efeito de interação face a face, de certa proximidade entre os interlocutores, acentuado em momentos em que, por exemplo, a câmara faz um close de um dos falantes, ou quando estes interagem 
com repórteres que informam do palco do acontecimento noticiado.

A configuração desse cenário muda, porém, quando se trata das interações na internet e, particularmente, no Facebook. Nesse caso, a notícia é captada pelo ouvinte, estando ele, provavelmente, sozinho, diante da tela do computador ou do celular. Sendo assim, bastaria, em princípio, que ele formasse a sua opinião em relação ao noticiado e a guardasse para si, como ocorreria, provavelmente, se a recebesse diante da tela do televisor. Um comentário da notícia diante do televisor só ocorreria, em princípio, se ele estivesse na companhia de alguém. No Facebook, porém, a própria plataforma on-line em que ocorre a divulgação de notícias e outras informações o convida para expressar seu ponto de vista. $\mathrm{E}$ esse convite é imediato, direto e pessoal, tão pessoal que, junto ao espaço disponibilizado para o comentário, aparece fotografia do ouvinte.

Esse fato, portanto, revela que, se já existe uma relação enunciativa entre falante e ouvinte na interação televisiva, essa enunciatividade se acentua no contexto da internet, particularmente, no contexto do Facebook, cuja plataforma foi concebida para relações face a face, de proximidade, conforme atesta a própria pergunta de entrada: "No que você está pensando agora?" ou "Deseja compartilhar uma atualização?”. É um eu que se dirige a um tu, instituindo um quadro de relações que convidam à informalidade, à conversa, à fala, em suma, à oralidade, ainda que por meio da escrita. É indiscutível, portanto, que a caracterização dos comentários, em conteúdo e forma, é diretamente condicionada por sua inserção no contexto da internet e do Facebook.

No entanto, dentro desse contexto, acreditamos haver ainda um condicionamento específico, que é o fato de os comentários no Facebook serem impulsionados uns pelos outros. Ao primeiro comentário segue um outro e, assim, sucessivamente, dependendo da candência do tema em pauta, se junta uma multidão, na qual todos se influenciam e se comovem mutuamente, gerando o que Barros (2016) denomina de "ondas" ou "tsunamis" de reações. É provável que a coragem de o indivíduo se manifestar, com a crueza que os nossos dados revelam, advenha mais da onda da massa do que de postura individual consciente.

Ao tratar do comportamento da massa, enquanto erupção de um grupo de pessoas, Canetti explica que,

[...] a massa destrói preferencialmente edifícios e objetos. Como frequentemente se trata de coisas quebradiças - como vidraças, espelhos, vasos, quadros, louça -, inclinamo-nos a acreditar que é justamente esse caráter quebradiço dos objetos que estimula a massa à destruição. Seguramente o ruído da destruição - o espatifar-se da louça, o tinir das vidraças contribui de modo considerável para o prazer que se tem nela [...]. O fato de ser tão fácil provocá-los intensifica-lhes a popularidade: todos gritam em uníssono, e o tinir é o aplauso dos objetos. [...] $\mathrm{O}$ barulho promete o fortalecimento pelo qual se espera, constituindo ainda um feliz presságio dos feitos que estão por vir (1995, p. 18). 
Da mesma forma como a massa que caminha por espaços físicos é estimulada a atacar elementos quebradiços como forma de fortalecimento, vemos que a irrupção do ódio tanto no caso da menina Dunja quanto no caso dos presidiários, advém desse ataque a elementos que carregam a semântica do ser quebradiço. Ora, a imagem da menina retrata uma criança frágil e que sofre todas os infortúnios de uma diáspora; os presidiários carregam o traço do encarceramento, o qual impede qualquer tipo de defesa de si, tanto do ponto de vista físico, quanto axiológico, uma vez que são subjugados por transgredirem os valores eufóricos da sociedade.

A menina refugiada e os presidiários são portadores das diferenças que provocam medo/ódio e contra as quais busca-se demarcar fronteiras. Eles são considerados como aqueles que podem causar danos, por não terem cumprido os pactos sociais, por terem desrespeitado os valores instituídos. Uma vez instituídos esses antissujeitos, emerge contra eles um sujeito altamente tomado pela paixão do ódio e que buscará declarar as ações necessárias decorrentes disso.

Destruir portas e janelas é destruir obstáculos, elementos que impedem o avanço da massa. Semelhantemente, o aniquilamento dos presidiários e da menina é para a massa a destruição de um obstáculo. Além disso, ambos constituídos como um referente, são objetos de "julgamento" e não sujeitos, pois não podem falar. Atacar elementos quebradiços é uma maneira da massa elevar sua força e adensar seu espírito de coesão.

No que concerne à manifestação de massa nos comentários do Facebook, cabe ainda registrar que ela se fortalece pelo fato de a mediação do celular ou do computador colocar o falante numa posição de segurança e conforto. Ele pode falar, mas seu corpo encontra-se protegido em outro espaço. Sua presença no espaço de interlocução é uma presença virtualizada. Segundo Amossy (2017, p. 173), na internet não se manifestariam mais "atores sociais, mas 'avatares', seres dotados de uma identidade fictícia no cyberspaço".

\section{Análise dos comentários}

Faremos, inicialmente, uma análise dos comentários favoráveis ao massacre, que, como dissemos, é nosso propósito principal. Num segundo momento, acrescentaremos observações sobre os comentários que se opõem à matança.

\section{Comentários a favor da matança}

Sempre no âmbito do cenário da enunciação definido, comecemos a análise, dando evidência inicial ao nível da expressão. Nessa perspectiva, destaca-se de imediato que os comentários, do ponto de vista conceptual da distinção ( MARCUSCHI, 2001; KOCH; OESTERREICHER, 2007), são fala e não escrita. É essa uma decorrência direta do cenário da enunciação que descrevemos. A proximidade dos 
internautas, todos movidos e comovidos pela presença no mesmo espaço virtual, leva-os a se manifestarem, quando não com expressões nominais, com enunciados em períodos simples, constituídos quase todos por orações absolutas ou coordenadas. Além disso é também próprio do caráter oral das manifestações a ausência de qualquer censura quanto às normas da língua escrita.

Com poucas exceções, os comentários exprimem reações fortemente, quando não exacerbadamente, carregadas de emoção à notícia dos 60 mortos. São reações inflamadas de júbilo pelas mortes ocorridas e, por isso, de incitação e apoio à matança. Muitos comentários iniciam com formas exclamativas da língua, próprias para a expressão das emoções de euforia, como mostram estes destaques:

[oba] menos 60 pra para mata i rouba [Aiiiiiiii], um troféu para quem me deu este presente de ano novo!

[Só isso], esses não faram mais mal a ninguém

[Tem nada não gente!] morreu poucos

[Nossa] não vou nem dormir de tanta tristeza

[Nossa] que raiva aaa so 80 !

[Que ótimo] .... que se matem!! Todos!!

[Que bom] 2017 começou bem 60 a menos.

[Pocha vida] 20 sòn sò isso
Os poucos comentários que não contêm uma formulação exclamativa explícita, exprimem seu regozijo pelas mortes no todo do enunciado. Na verdade, os enunciados de nosso estudo, não são, a rigor, comentários, já que esse termo se define como um texto minimamente apreciativo, explicativo-descritivo ou argumentativo. Os enunciados aqui em foco vêm esvaziados de racionalidade explicativa, argumentativa e justificadora. Não há neles o distanciamento do observador analista, mas, sim, o imediatismo do enunciador apaixonado que escancara o eu, aqui e agora, num rompante de ódio, extravasado num grito de euforia pela matança noticiada. É por isso que falamos em "irrupção de ódio", no título deste trabalho. Por irrupção entendemos a expressão de um sentimento carregado de intensa emoção, no caso, de intensa emoção de ódio.

Revela-se na explosão da euforia pela morte dos detentos um traço de excesso, de exagero, enfim, de intensidade exacerbada, que, segundo Barros, caracteriza os discursos da internet, em especial os discursos do ódio:

Os discursos intolerantes em geral e os discursos na internet, também em geral, caracterizam-se pelo excesso: de intensidade, de tensão passional, de extensão, de complexidade. Dessa forma, os discursos intolerantes e preconceituosos na internet ampliam esses excessos e constroem as ondas, ou melhor, os tsunamis de ódio de que imprensa e sociedade tanto falam nos tempos atuais (2016, p. 13).

Os nossos dados confirmam inteiramente a constatação da autora. Talvez se 
devesse só relativizar sua afirmação de que os "discursos da internet em geral" se caracterizam pelo excesso. Há, evidentemente, muitos discursos serenos na internet, até mesmo no Facebook, mas os de ódio e intolerância são indiscutivelmente exagerados, e muitos, como os que a autora analisa no texto referido, pecam pelo "exagero do exagero".

A ausência ou ao menos a atenuação da racionalidade nos comentários vem também atestada no recurso frequente às frases feitas e estereotipadas, como estas:

Bandido bom é 7 palmos abaixo da terra.

O destino é pra quem procura!

Eles se merecem.

Bandido bom é bandido morto

Cada um tem o que merece

$\mathrm{O}$ que se faz aqui se paga

São enunciados construídos em torno de um verbo no presente omnitemporal ou gnômico, próprio, segundo Fiorin (2016, p. 134), "para enunciar verdades eternas ou que se pretendem como tais". É a forma verbal utilizada nos provérbios e ditados populares. Por serem de circulação corrente no discurso cotidiano, eles não têm autoria. Não entram na constituição do enunciado de um eu que analisa e argumenta. Pelo contrário, se bastam a si, dispensando a argumentação, a análise, a reflexão na medida em que antecipam a "verdade" já definida como princípio consensual.
$\mathrm{E}$ é justamente por isso que encontram sintonia no âmbito dos discursos movidos pela emoção, em especial nos discursos coletivos. Fazem, de certa forma, o papel dos banners e das faixas dos movimentos de massa, nas passeatas e desfiles.

No que respeita ao conteúdo dos comentários, fixemo-nos, principalmente, em alguns percursos figurativos e temáticos. Quando os internautas justificam a matança dos sessenta detentos, salta aos olhos o tema da desqualificação humana (da desumanização) dos mortos, figurativizado por um percurso de atributos e denominações do tipo: "rebanho di cabrunco", "vermes", "vagabundos", "besta", "podridão".

Conflui para esse mesmo percurso temático do desprezo e da desqualificação humana um percurso de figuras que intensificam a desumanização, revestindo o tema da aniquilação humana. Destacam-se aí figuras como "inferno", "fogo" e "limpeza" muito recorrentes em discursos de ódio racista, de limpezas étnicas de guerras recentes e, também, na alusão ao fogo feita na ressignificação da fotografia da refugiada Dunja. Vejam-se exemplos extraídos de nossos dados:

vao voubar nu inferno

Agora é só juntar tudo em um buraco e meter fogo

Esses vermes tem que ir para o inferno, que o Satanás o tenha $\mathrm{O}$ ano começou bem com a limpeza Grande coisa esses que morreram 
Um outro tema que nossos dados revelam é o da completude/incompletude da aniquilação com figuras que remetem ao desejo da realização plena da matança.

Só sessenta imundos foi pouco.

Pena que não se matarão a maioria.

Tem nada não gente! morreu poucos

Só isso, esses não faram mais mal a ninguém

se fosse mais, a economia seria maior!

so 80 la tem mas 2000 sacooo ve se na proximo faz o servico certo acaba com tudo

Tem que processar o governo por ter interrompido!

que se matem!! Todos!!

sò isso,como é o Brasil,kkkkkkk Podia ser todos mortos

Menos 60 !!! Tinha que ter umas 20 chacinas dessa por dia e ainda incluir os diretos humanos na linha de frente

\section{Comentários contrários à matança}

Por fim, apresentamos uma breve análise relativa aos comentários em sentido contrário aos anteriores. Podemos reuni-los do ponto de vista discursivo em três categorias: os de caráter religioso, os referentes à instituição familiar e os relativos à repugnância da imagem. Seguem três comentários exemplificando respectivamente cada uma das categorias: a) "Que triste. Mas o que mais me choca é a falta do ser humano nas pessoas, tanto de quem está dentro quanto de quem está fora do sistema carcerário, pessoas essas que se acham tanto ao ponto de julgar, de dizer "mereceu, tava lá dentro mesmo", quem é você pra julgar? Querendo ou não somos todos seres humanos e eu prezo pela vida de todos, pois não sou Deus para querer tirar a vida do outro, seja lá quem for! Eu não pago o mau com o mau, sou diferente, eu espero a justiça aqui da terra e de Deus! É triste o que esses tipos de pessoas fazem e por isso estão ali, mas eu não sou capaz de desejar a morte de uma pessoa. Ou querer devolver com a mesma maldade!!"

b) "So olhando os comentários pelo menos respeitem as famílias pai nao bota filho no mundo $\mathrm{p}$ vira bandido respeitem a dor dos familiares gente"

c) "Pessoal acha bacana, mas se ves verem as imagens não vão nem conseguir dormir...A coisa foi feia, ainda bem que não mataram nenhum agente penitenciário -que por sinal são pai de família."

No primeiro exemplo, o eu que enuncia posiciona-se de modo a defender valores contrários aqueles defendidos pela grande massa, pois não prega o aniquilamento dos presidiários. Para defender seus valores, esse eu cria uma, digamos, "re-humanização" dos presidiá- 
rios e vale-se de figuras que remetem ao tema da religião, uma vez que para ele só Deus pode julgar ou tirar a vida das pessoas.

No segundo comentário, evoca-se a figura dos familiares, tematizando por meio da relação parental, a dor de se perder um filho.

Já o terceiro, argumenta contra a matança de maneira indireta, evocando a repugnância da imagem da morte, que poderia inclusive, ter se estendido à agentes penitenciários. Ao final desse comentário, vemos também o uso da ideia da relação parental como forma de argumento.

Em síntese, vemos nesses exemplos que, da mesma forma como ocorre nos discursos a favor da matança, não há uma reflexão mais aprofundada. Em geral, esses comentários, embora tenham um tom mais brando em relação ao caso em questão, expressam-se por meio de enunciados curtos e definitivos calcados em ideias de senso comum. É importante destacar também que, em meio a massa que coaduna com a aniquilação dos presidiários, esses comentários são bastante raros e não recebem curtidas. Logo, ou são ignorados, ou são facilmente silenciados por meio de respostas também pouco ponderadas, como: "Leva pra sua casa então os restantes", "Então Deus queira que nunca aconteça nada com sua família, porque se um desses aí tirasse a vida de um familiar ou um amigo ou estupro, pensaria bem diferente", "Nossa coitadinhos sempre tem um idiota, para achar que sao coitados, sempre vai ter opnioes diferente, e essa é a minha gostem ou não gostem, bandido bom é bandido morto".

\section{Considerações finais}

A cenografia é essencial para os discursos do Facebook, pois toda a organização do suporte material é sempre predefinida dentro de uma mesma estrutura. As escolhas de expressão e os posicionamentos assumidos pelo sujeito da enunciação definem uma cenografia pessoal. Contudo, vemos em nossa análise a tendência à repetição. Há uma cenografia da massa, que repete os discursos em uníssono e repele tudo aquilo que não reflete sua voz.

Por se manifestar num cenário de enunciação configurado pelas interações no Facebook, emerge dos comentários um enunciador apaixonado, isto é, um enunciador que reage numa explosão de alegria pela matança noticiada, movido, ao mesmo tempo, pela notícia em si e pelo fato de se manifestar num espaço coletivo de influência mútua. As características técnicas do suporte da internet, como a presença virtual do falante, a velocidade e a amplitude da divulgação impelem os usuários do Facebook a manifestar-se constantemente. Adensa-se, dessa forma, a massa que manifesta uma única voz e tonificam-se, ao máximo, as paixões e os sentidos manifestados nos discursos. As individualidades dissolvem-se numa 
grande massa que, cada vez mais espessa, pronuncia o ódio a toda força.

A expressão de alegria pela morte de pessoas mediada pela plataforma do $\mathrm{Fa}$ cebook atribui à enunciação um grau de intensidade máxima ao discurso do ódio, que fica ratificado e destacadamente intensificado na análise dos percursos figurativo-temáticos. Mesmo que existam discursos contrários a esse ódio, eles tornam-se raros e apagados em meio à força elocutória. Criam-se verdadeiros nichos entre iguais e, certamente, diferenças de qualquer ordem são impetuosamente repelidas.

\section{The burst of hate on the Internet: discursive traits of its manifestation on Facebook}

\section{Abstract}

This paper brings a study on hate on the Internet, with special focus on the discursive traits of its manifestations on Facebook. The starting point of discussion is the manifestations from Internet users about the massacre of prisoners in Manaus that happened in January 2017. The massacre gave rise to different controversial issues. The main issue was embodied on the polarization of opinions: on one pole, there were those favorable to the thorough elimination of the prisoners, and on the other, there were those against the massacre. In light of the tenets of enunciation, there is, at first, the interactive-enunciative nature of the Internet users' manifestations. After having set this interactional scene, this paper focuses on particular evidence to thematic and figurative processes that structure both the hate and massacre speech and the opposing manifestations to these hate speeches.

Keywords: Discourse. Hate speech. Facebook. Enunciation.

\section{Notas}

1 Das Bild illustriert das wichtigste politische Thema des vergangenen Jahres auf besondere Weise: Es geht in der Flüchtlingskrise nicht nur um Leben und Tod, Sorgen und Ängste, Staatskrisen und Grenzzäune, es geht um Menschen, um Kinder, die sich an denselben Dingen freuen wie alle anderen Kinder auch. Das Bild berührt den Betrachter. Es gibt Hoffnung (disponível em: http://wien.orf.at/news/ stories/2781422/>. Acesso em: 15 jul. 2017).

2 Unter Hate Speech - hier übersetzt mit „Hassrede“ - wird im Allgemeinen der sprachliche Ausdruck von Hass gegen Personen oder Gruppen verstanden, insbesondere durch die Verwendung von Ausdrücken, die der Herabsetzung und Verunglimpfung von Bevölkerungsgruppen dienen.

3 Mit Sprache kann man nicht nur auf die Welt Bezug nehmen, mit ihr kann man nicht nur zur Gewalt aufrufen, sondern ihr Gebrauch kann selbst eine destruktive Form von Gewaltausübung sein. Mittels Sprache werden Menschen stigmatisiert, diskriminiert und dämonisiert. Insbesondere die sogenannte "Hassrede“ zeichnet sich dadurch aus, dass Menschen in ihrer Würde verletzt und als dehumane $\mathrm{Ob}$ jekte diskriminiert werden, dass sie als böse, unnütze Kreaturen kategorisiert werden, die keine Existenzberechtigung haben.

4 Disponível em: <https://www.facebook.com/JornalHoje/posts/1300073530059287?comment_tr acking $=\% 7 \mathrm{~B} \% 22 \operatorname{tn} \% 22 \% 3 \mathrm{~A} \% 22 \mathrm{O} \% 22 \% 7 \mathrm{D}>$. Acesso em: 18 jul. 2017.

5 Não devemos aqui entender "cenário" na apreensão do senso comum: conjunto de elementos visuais que configuram o espaço onde se desenvolve a peça teatral. Embora haja um empréstimo semântico, usamos o termo "cenário" da maneira como postulado por Maingueneau, para quem a "situação de enunciação não é, com efeito, um simples quadro empírico, ela se constrói como cenografia por meio da enun- 
ciação. [...] O discurso implica um enunciador e um co-enunciador, um lugar e um momento da enunciação que valida a própria instância que permite a sua existência" (2006, p. 51).

6 Tanto esta foto quanto a seguinte encontram-se em: <https://www.facebook.com/JornalHoje/ posts/1300073530059287?comment_trackin$\mathrm{g}=\% 7 \mathrm{~B} \% 22 \operatorname{tn} \% 22 \% 3 \mathrm{~A} \% 22 \mathrm{O} \% 22 \% 7 \mathrm{D}>$. Acesso em: 18 jul. 2017.

\section{Referências}

AMOSSY, R. A apologia da polêmica. São Paulo: Contexto, 2017.

BARROS, D. L. P. de. Estudos discursivos da intolerância: o ator da enunciação excessivo. Cadernos de Estudos Linguísticos, Campinas: Unicamp, v. 58, n. 1, p. 7-24, jan./abr. 2016.

BARROS, D. L. P. de. Efeitos de oralidade no texto escrito. In: PRETI, D. (Org.). Oralidade em diferentes discursos. São Paulo: Humanitas, 2006. p. 57-84.

CANETTI, E. Massa e poder. São Paulo: Cia. das Letras, 1995.

FIORIN, J. L. As astúcias da enunciação: as categorias de pessoa, espaço e tempo. São Paulo: Contexto, 2016.

KOCH, P.; OESTERREICHER, W. Schriftlichkeit und kommunikative Distanz. Zeitschrift für germanistische Lingusitik, v. 35, n. 21, p. 346-375, 2007.

MAINGUENEAU, D. Cenas da enunciação. Curitiba: Criar, 2006.

MARCUSCHI, L. A. Da fala para a escrita: atividades de retextualização. São Paulo: Cortez, 2001.

MEIBAUER, J. (Org.). Hassrede/Hate Speech: Interdisziplinäre Beiträge zu einer aktuellen Diskussion. Gießener Elektronische Bibliothek, p. 143-164, 2013. Disponível em: <http://geb. uni-giessen.de/geb/volltexte/2013/9251/>. Acesso em: 20 jun. 2017.

SCHWARZ-FRIESEL, M. "Dies ist kein Hassbrief - sondern meine eigene Meinungüber
Euch!“ - Zur kognitiven und emotionalen Basis der aktuellen antisemitischen Hassrede. In: MEIBAUER, Jörg (Org.). Hassrede/Hate Speech: Interdisziplinäre Beiträge zu einer aktuellen Diskussion. Gießener Elektronische Bibliothek, p. 143-164, 2013. Disponível em: <http://geb.uni-giessen.de/geb/volltexte/2013/9251/>. Acesso em: 20 jun. 2017.

STROBEL, Cornelius. Die Grenzen des Dialogs: Hate Speech und politische Bildung. In: KASPAR, Kai; GRÄSSER, Lars; RIFFI, Aycha (Org.). Online Hate Speech: Perspektiven auf eine neue Form des Hasses. Marl: Kopaed Verlagsgmbh, 2017. 